EPJ Web of Conferences 33, 01009 (2012)

DOI: $10.1051 /$ epjconf/20123301009

(c) Owned by the authors, published by EDP Sciences, 2012

\title{
Global warming potential impact of bioenergy systems
}

\author{
D. Tonini ${ }^{1}$, L. Hamelin ${ }^{2}$, H. Wenzel ${ }^{3}$ and T. Astrup ${ }^{4}$ \\ 1,4 Technical University of Denmark (DTU), Lyngby, Denmark \\ ${ }^{2,3}$ Southern Denmark University (SDU), Odense, Denmark
}

\begin{abstract}
Reducing dependence on fossil fuels and mitigation of GHG emissions is a main focus in the energy strategy of many Countries. In the case of Demark, for instance, the long-term target of the energy policy is to reach $100 \%$ renewable energy system. This can be achieved by drastic reduction of the energy demand, optimization of production/distribution and substitution of fossil fuels with biomasses. However, a large increase in biomass consumption will finally induce conversion of arable and currently cultivated land into fields dedicated to energy crops production determining significant environmental consequences related to land use changes. In this study the global warming potential impact associated with six alternative bioenergy systems based on willow and Miscanthus was assessed by means of life-cycle assessment. The results showed that bioenergy production may generate higher global warming impacts than the reference fossil fuel system, when the impacts from indirect land use changes are accounted for. In a life-cycle perspective, only highly-efficient co-firing with fossil fuel achieved a (modest) GHG emission reduction.
\end{abstract}

\section{Introduction}

The long-term target of the energy policy in Denmark is to achieve a 100\% renewable energy system by 2050 [1]. Several studies have been conducted to optimize such a system, and these all underlined the need for a biomass potential of about $30 \%$ to $50 \%$ of the overall primary energy demand [1-5]. The principal reason why biomass is needed into the energy system lie in the fact that it is storable and can therefore be used for balancing the fluctuating energy production from wind and solar power $[1,3,5,6]$.

However, biomass is not unlimited in supply, and its production involves considerable environmental costs. These are mostly related to land use changes (LUC) [7], i.e. the conversion of land from one use (e.g. forest, grassland or food/feed crop cultivation) to another use (e.g. energy crop cultivation). LUCs are typically divided into direct (dLUC) and indirect (iLUC). The iLUC refers to the market forces-driven land use changes occurring as a reaction to food (or feed) displacement on the food (or feed) market $[8,9]$. Instead, the dLUC represents the change in the land use allocation of a given region that caused this displacement to occur in the first place.

The production of perennial energy crops (e.g. Miscanthus, willow, perennial ryegrass, poplar, etc.) in place of annual crops (e.g. maize, barley, etc.) minimizes the global warming dLUC impact thanks to the higher yield (and thus C uptake from the atmosphere) which also determines a beneficial increase of the soil organic carbon stock (SOC). Furthermore, requirement of fertilizers for these crops is low [10] leading to lower eutrophication impacts [11]. For these reasons, this study focuses only on perennials.

The goal of this study was thus to assess the global warming potential impacts associated with the production of bioenergy (heat and electricity) from 1 hectare (ha) of Danish arable land cultivated with willow and Miscanthus, considering three different biomass-to-energy (BtE) technologies: i) anaerobic mono-digestion, ii) combustion in small-to-medium scale biomass combined heat and power (CHP) plants and iii) co-firing in large scale coal-fired CHP plants.

\section{Methodology: goal, scope, functional unit and impact assessment method}

The global warming potential assessment was evaluated by consequential LCA $[12,13]$. The term consequential refers to the fact that in the LCA the system boundary is expanded to include all consequences arising from the changes induced by the technological scenarios evaluated as compared to the reference fossil fuel scenario where the land was used for food/feed cultivation [14]. The functional unit of the study was 1 ha of Danish agricultural land. The geographical scope was Denmark (including the legislative context (e.g. for fertilization)). The temporal scope was 20 years. 
The impact assessment was carried out according to the Danish EDIP 2003 method [15,16]. Foreground LCA data essentially included Danish-specific data. Background (i.e. generic) LCA data were based on the Ecoinvent v.2.2 database. The assessment was facilitated with the LCA software SimaPro 7.3.2 [17].

The scenarios assessed considered two perennial crops (Miscanthus and willow) and three energy conversion technologies (anaerobic digestion, combustion in small-to-medium scale biomass CHP plants and co-firing in large scale coal-fired CHP plants). A total of 6 scenarios have therefore been assessed. An overview of the system modeled as well as the boundary conditions for the case of anaerobic mono-digestion is presented in Figure 1. For the other scenarios (combustion and co-firing) the LCA system modeled is the same except for fertilizers substitution and use on land which are not of concern.

For all BtE technologies, the energy produced was assumed converted to electricity and heat, thereby substituting the production of marginal heat and power. In the present study, the marginal electricity source was assumed to be from coal-fired power plants, and the marginal heat from natural gas based domestic boiler.

As illustrated in Figure 1, the digestate produced from anaerobic digestion was used as a fertilizer (for N, P, and K), which avoided marginal mineral N, P and $\mathrm{K}$ fertilizers to be produced and used, based on the content of N, P and K of the digestate. The marginal N, P and $\mathrm{K}$ fertilizers considered were calcium ammonium nitrate, diammonium phosphate and potassium chloride, respectively, conformingly with [11,14].

The treatment of bottom and fly ash as well waste water from the BtE conversion plants was disregarded as previous studies pointed out that such processes generally lead to negligible impacts as compared to the others (e.g. iLUC) involved in the bioenergy chain. Similarly, transportation and capital goods were not included in the assessment.

It was assumed that the land needed to grow the energy crops was (arable) Danish land. As a consequence, one marginal crop cultivated today was assumed displaced. This was assumed spring barley, based on [18-20]. The dLUC consequences have been calculated as the difference in cultivating the selected energy crops instead of spring barley (Figure 1). The environmental impacts from spring barley were based on [11]. Based on recent studies [9,21,22], such a replacement will cause a relative increase in agricultural prices, leading finally to increase the production elsewhere. As in recent iLUC studies [8,23,24], this LCA included the (global warming) impacts of the conversion of 'new land' only. In the present, the results of [21] for Denmark have been used as a proxy to estimate the quantity of land which was converted and the corresponding biomes types. To estimate the $\mathrm{CO}_{2}$ impact of land conversion, the soil and vegetation carbon data published in [25] have been used, as well as the methodology published in [9].

\section{Life-cycle inventory}

\subsection{Crops inventory}

The life cycle inventory of all crops was based on a recently published Danish consequential life cycle inventory [11]. This included all processes occurring during the cultivation stage (up to harvest). A sandy loam soil has been considered for all crops with precipitations of $964 \mathrm{~mm} \mathrm{y}^{-1}$. For all crops, the fertilization operations were performed in conformity with Danish regulations [26,27] which require an upper ceiling for the amount of $\mathrm{N}$ to be applied on the field. The $\mathrm{N}$ demand of the crops is considered to be fulfilled by $50 \%$ animal manure and 50\% mineral fertilizers, except for willow, which can only be fertilized with whether $100 \%$ slurry (harvest years) or 100\% mineral fertilizers (other years), since slurry spreading is only possible in harvest years under Danish conditions. The mineral fertilizers considered are the marginal ones, as earlier described. Further details are available in [11].

\subsection{BtE technologies: anaerobic mono-digestion, combustion and co-firing}

Follows a brief overview of the BtE conversion technologies modeled in the LCA

With respect to anaerobic mono-digestion, a generic mesophilic digestion plant was modeled, where the energy crops were assumed digested without any co-substrates. It was assumed that the required amount of nitrogen and phosphorous (as well as other indispensable micronutrients) was added to the process in order to reach the optimal proportion of $\mathrm{C}, \mathrm{N}$ and $\mathrm{P}$ in the mix (e.g. for $\mathrm{C} / \mathrm{N}$ this was 16-20). The consumption of $\mathrm{N}$ and $\mathrm{P}$ was accounted for in the LCA. The consumption of other micronutrients needed was not accounted for. For Miscanthus and willow, the data for methane yield (300 $\left.\mathrm{Nm}^{3} \mathrm{t}^{-1} \mathrm{VS}\right)$ were based on [28]. Emissions of biogenic $\mathrm{CO}_{2}$ were estimated as a function of the biogenic $\mathrm{CH}_{4}$ releases, based on the methodology described by [29]. Based on this, the ratio $\mathrm{CH}_{4} / \mathrm{CO}_{2}$ was found to correspond to 0.6 for willow and 0.5 for Miscanthus. The consumption of electricity and heat to operate the biogas plant was assumed equal to $40 \mathrm{kWh} \mathrm{t}^{-1} \mathrm{DM}$ and $0.6 \mathrm{GJ} \mathrm{t}^{-1} \mathrm{DM}$, respectively, based on [32]. Therefore, the overall thermal energy required to maintain mesophilic conditions in the reactors varied between 70 and 84 GJ ha ${ }^{-1}$, depending on the crop. The fugitive emission of methane was estimated to $1 \%$ of the methane produced, based on recent LCA studies (among others: [14]). The biogas generated from anaerobic digestion used in a gas engine with an average electrical efficiency of 38\%, based on [30]. The total energy efficiency was set to $90 \%$, thus raising heat recovery efficiency to $52 \%$. The total energy efficiency was based on [31].

For direct biomass combustion, a generic small-to-medium scale (3-90 MW of net power output) biomass CHP plant was modeled based on a number of reviewed biomass CHP plants established essentially in Denmark. The average net electricity 
efficiency of Danish biomass CHP plants was assumed 27\%. The consumption of resources and materials to operate the plant was based on [32].

Co-firing of the crops was modeled as direct co-firing with pulverized coal, assuming a large-scale CHP power plant. The differences between direct combustion and co-firing regarded the pretreatment of the biomass and the energy efficiency of the process. The net electrical efficiency was set to $38 \%$, based on an existing co-firing plant [33]. For the three technologies considered, the air emissions (other than $\mathrm{CO}_{2}$ ) were based on [34].

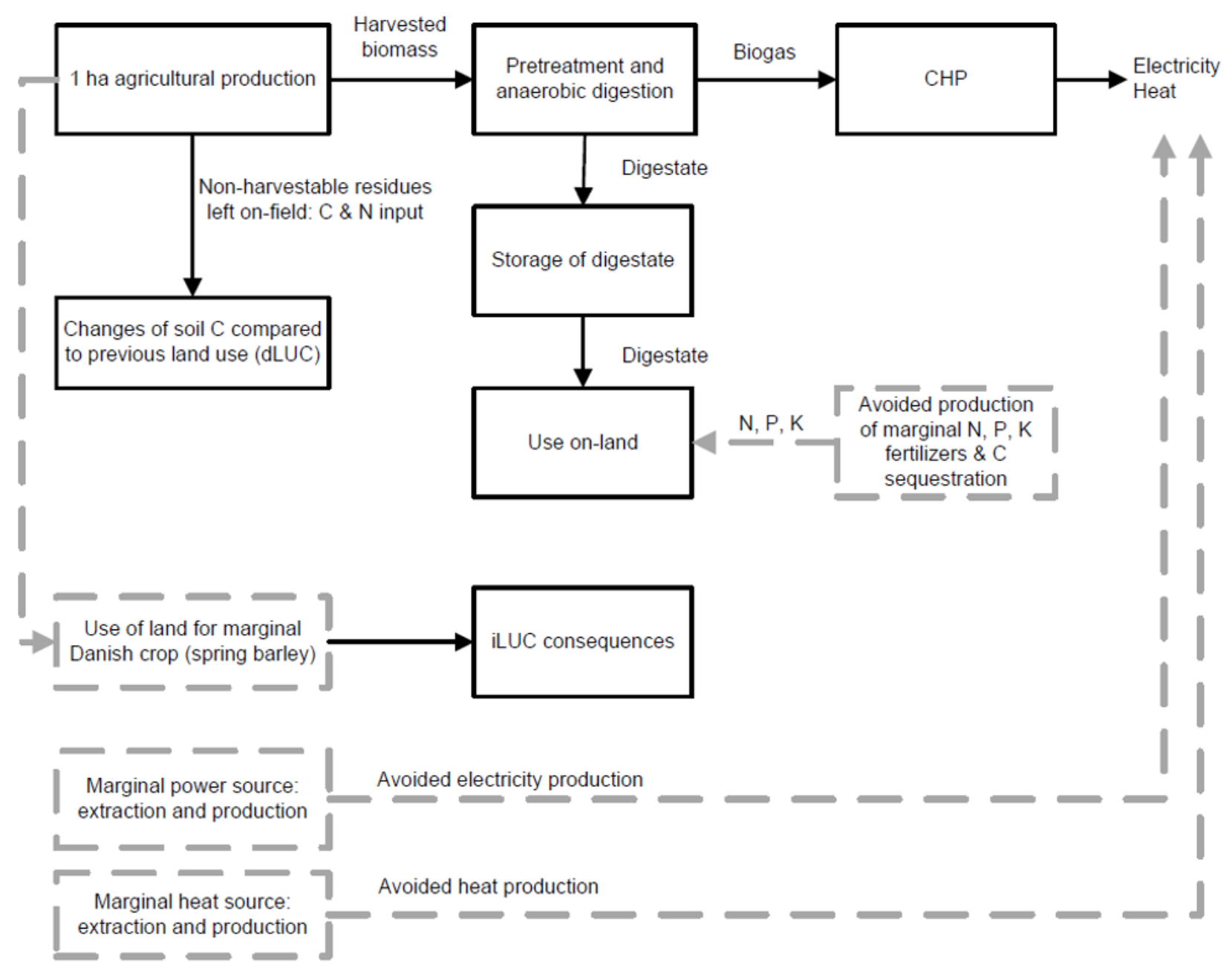

Fig. 1. LCA flow chart for the case of anaerobic mono-digestion.

\subsection{Others: pre-treatments and use on land}

Prior to anaerobic digestion a steam pre-treatment was needed in order to process lignocelluloses-rich crop such as willow and Miscanthus and increase their biodegradability. The pre-treatment was modeled according to [28]. Prior to combustion and co-firing willow (water content at harvest 50\%) was assumed to be dried (to $85 \% \mathrm{DM}$ ) and stored with overall DM losses of 5\% [35]. Miscanthus (DM 90\% at spring harvest) was assumed stored indoor with total DM losses of 5\% [36]. The corresponding $\mathrm{CO}_{2}$ emissions were calculated based on the assumption that the carbon was aerobically degraded to $\mathrm{CO}_{2}$ proportionally to the content in the dry matter (i.e. C loss $(\mathrm{kg})=\mathrm{DM}$ loss $(\mathrm{kg})$ x C content $(\%))$. Co-firing also required a pre-treatment of pelletization and subsequent milling of the crops (i.e. pulverization).

The digestate from anaerobic digestion was assumed to substitute for $\mathrm{N}, \mathrm{P}$ and $\mathrm{K}$ mineral fertilizers. The substitution was modeled as described in [14], for a pig farm. The direct emission of $\mathrm{N}_{2} \mathrm{O}$ were calculated equal to $1.5 \%$ of the $\mathrm{N}$ applied with the digestate based the average value of the range provided by the IPCC approach [37] for application on land of digestate; the emission of $\mathrm{NH}_{3}$ was calculated equal to $11 \%$ as average of a range of values suggested by [38-41]. The indirect $\mathrm{N}_{2} \mathrm{O}$ emissions were quantified based on IPCC [37]. The share of the applied $\mathrm{C}$ that is emitted as $\mathrm{CO}_{2}$ was based on the findings of [41]. Based on this, it was assumed that $74 \%$ of the $C$ applied was emitted within 20 years. 


\section{Results and Discussion}

The global warming potential associated with the six bioenergy scenarios assessed is shown in Figure 2. The Figure shows the impact associated with the assessed bioenergy scenario and the impact corresponding to the reference fossil fuel scenario (absolute results). Therefore, the assessed bioenergy scenario is beneficial (GHG-wise) compared to the reference only if the relative column is lower (i.e. savings are achieved) than the corresponding reference column.

From Figure 2 it is evident that only co-firing of willow achieved (modest) global warming savings compared to the fossil fuel reference. The higher performance of this technology (compared to the alternatives) was mostly related to the higher electricity efficiency. However, these savings were negligible compared to any previous study on bioenergy systems. The reason for that lies on the fact that this LCA accounted for iLUC impacts which magnitude dramatically affected the overall results. The iLUC was quantified as 309 t CO$_{2}$-eq. ha $^{-1}$ based on the approach earlier described.

All in all, anaerobic mono-digestion was the least desirable option global warming-wise. In fact, in addition to the lower energy production (caused by the low biodegradability of the crops) as compared to combustion and co-firing, use on land of the digestate was also an important source of $\mathrm{C}$-emissions; this was again a direct consequence of the lower biodegradability of these crops which finally implied a large share of the input carbon to be applied on land (and further released to the atmosphere) after energy conversion. Application on land of the digestate may in fact save mineral fertilizers use and production; however, the non-converted carbon applied on land is mostly released to the atmosphere and it therefore does not represent a relevant sink of carbon with respect to global warming.

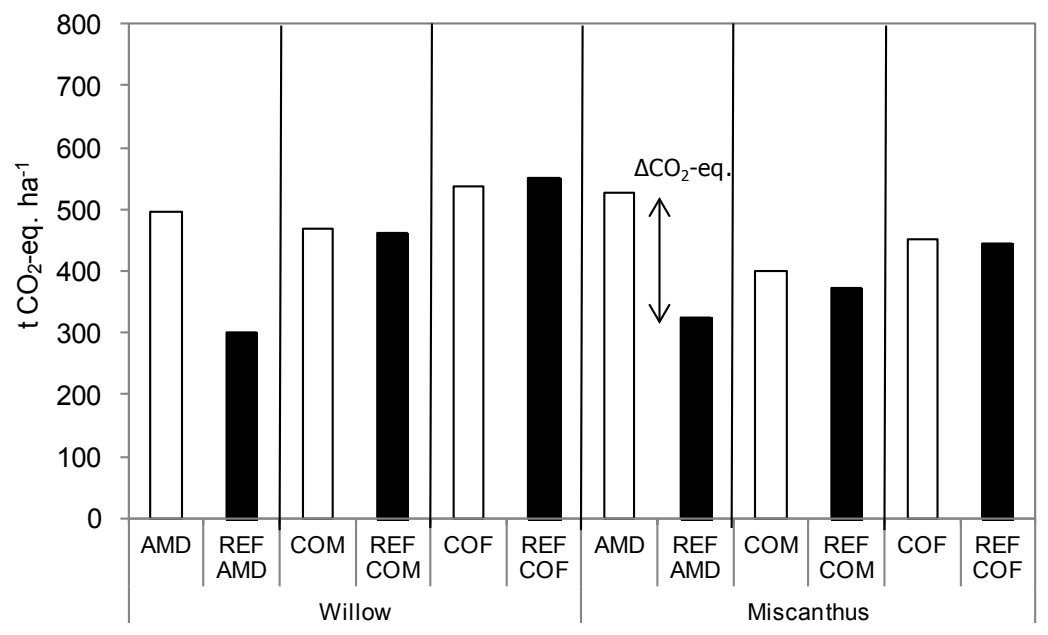

Fig 2. Global warming potential of the assessed scenarios. AMD: anaerobic mono-digestion; COM: combustion; COF: co-firing; REF AMD: reference scenario of AMD; REF COM: reference scenario of COM; REF COF: reference scenario of COF.

\section{Conclusion}

A number of bioenergy scenarios based on willow and Miscanthus were assessed by LCA. The results indicated that only highlyefficient co-firing may lead to (though modest) GHG savings compared to the reference fossil fuel system. However, the magnitude of these savings was modest and the overall savings achieved negligible as compared to the values reported by any previous study on bioenergy. The reason of this lies in the fact that most previous studies on bioenergy systems did not account for iLUC which were instead quantified in the present.

\section{Acknowledgements}

The work presented in this paper is a result of the research project Coherent Energy and Environmental System Analysis (CEESA), partly financed by The Danish Council for Strategic Research. 
$2^{\text {nd }}$ European Energy Conference

\section{References}

[1] H. Lund, B.V. Mathiesen, Energy system analysis of $100 \%$ renewable energy systems: The case of Denmark in years 2030 and 2050, Energy 34 (2009) 524-531.

[2] D. Tonini, T. Astrup, Life-cycle assessment of biomass-based energy systems: a case study for Denmark, Appl. Energy (accepted) (2012).

[3] B.V. Mathiesen, H. Lund, K. Karlsson, 100\% Renewable energy systems, climate mitigation and economic growth, Appl. Energy 88 (2011) 488-501.

[4] B.V. Mathiesen, H. Lund, P. Noergaard, Integrated transport and renewable energy systems, Utilities Policy 16 (2008) 107-116.

[5] B.V. Mathiesen, H. Lund, F.K. Hvelplund, D. Connolly, N.S. Bentsen, D. Tonini, P.E. Morthorst, H. Wenzel, T. Astrup, N.I. Meyer, M. Münster, P.A. Østergaard, B. Bak-Jensen, M.P. Nielsen, E. Schaltz, J.R. Pillai, L. Hamelin, C. Felby, K. Heussen, P. Karnøe, J. Munksgaard, L. Pade, F.M. Andersen, K. Hansen, CEESA 100\% Renewable Energy Scenarios towards 2050, Aalborg University. Available from: http://www. ceesa. plan. aau. dk (accessed December 2011) (2011).

[6] H. Wenzel, Breaking the Biomass Bottleneck of the Fossil Free Society, Concito, Frederiksberg, Denmark ID: 302 (2010).

[7] T.D. Searchinger, Biofuels and the need for additional carbon, Environmental Research Letters 5 (2010) 024007-024007.

[8] R. Edwards, D. Mulligan, L. Marelli, Indirect land use change from increased biofuels demand. Comparison of models and results for marinal biofuels production from different feedstocks, EUR 24485 (2010).

[9] Searchinger T., Heimlich R., Houghton R.A., Dong F., Elobeid A., Fabiosa J., Tokgoz S., Hayes D., Yu T.-H., Use of U.S. croplands for biofuels increases greenhouse gases through emissions from land-use change, Science 319 (2008) 1238-1240.

[10] C.V. Beale, S.P. Long, Seasonal dynamics of nutrient accumulation and partitioning in the perennial C4-grasses Miscanthus x giganteus and Spartina cynosuroides, Biomass \& bioenergy 12 (1997) 419-428.

[11] L. Hamelin, U. Joergensen, B.M. Petersen, J.E. Olesen, H. Wenzel, Modelling the environmental consequences of direct land use changes from energy crops in Denmark: a consequential life cycle inventory, GCB Bioenergy (2012).

[12] ISO 14040, Environmental Management-Life Cycle Assessment-Principles and Framework, 2nd ed. (2006).

[13] ISO 14040, Environmental Management-Life Cycle Assessment-Requirements and Guidelines, 1st ed. (2006).

[14] L. Hamelin, M. Wesnaes, H. Wenzel, B.M. Petersen, Environmental Consequences of Future Biogas Technologies Based on Separated Slurry, Environ. Sci. Technol. 45 (2011) 5869-5877.

[15] M. Hauschild, J. Potting, Spatial differentiation in Life Cycle impact assessment - The EDIP2003 methodology, Environmental News No. 80 (2005).

[16] H. Wenzel, M.Z. Hauschild, L. Alting, Environmental Assessment of Products, Volume 1, (1997).

[17] Pre' Consultants, Simapro 7.1, www. pre. nl. (accessed 2009).

[18] B. Weidema, N. Frees, A.M. Nielsen, Marginal production technologies for Life Cycle Inventories, Int J Life Cycle Assess 4 (1999) 48-56.

[19] J.H. Schmidt, System delimitation in agricultural consequential LCA - Outline of methodology and illustrative case study of wheat in Denmark, The international journal of life cycle assessment 13 (2008) 350-364.

[20] R. Dalgaard, J. Schmidt H., N. Halberg, P. Christensen, M. Thrane, W. Pengue A., LCA of Soybean Meal, International Journal of Life Cycle Assessment 13 (2008) 240-254.

[21] J.H. Kloeverpris, Consequential life cycle inventory modelling of land use induced by crop consumption, $P h D$ thesis, Technical University of Denmark (DTU), Lyngby, Denmark. (2008).

[22] R. Edwards, S. Szekeres, F. Neuwahl, V. Mahieu, Biofuels in the European context: facts and uncertainties, (2008).

[23] W. Tyner, F. Taheripour, Q. Zhuang, D. Birur, U. Baldos, Land Use Changes and Consequent CO2 Emissions due to US Corn Ethanol Production: A Comprehensive Analysis, (2010).

[24] D. Laborde, Assessing the Land Use Change Consequences of European Biofuel Policies, International Food Policy Institute, Washington, DC, (USA) (2011).

[25] R. Müller-Wenk, M. Brandao, Climatic impact of land use in LCA - carbon transfers between vegetation/soil and air, The International Journal of Life Cycle Assessment 15 (2010) 172-182.

[26] Danish Ministry of Food, Agriculture and Fisheries, Plantedirektoratets bekendtgoerelse nr. 786 af 22. juli 2008 om jordbrugets anvendelse af goedning og om plantedaekke i planteperiode 2008/2009, (2008).

[27] Danish Ministry of Food, Agriculture and Fisheries, The Danish Plant Directorate. Vejledning om goedsknings-og

harmoniregler. Planperioden 1.august 2009 til 31.juli 2010, (2009). 
[28] H. Uellendahl, G. Wang, H.B. Moller, U. Jorgensen, I.V. Skiadas, H.N. Gavala, B.K. Ahring, Energy balance and cost-benefit analysis of biogas production from perennial energy crops pretreated by wet oxidation, Water Science and Technology 58 (2008) 1841-1847.

[29] L. Hamelin, M. Wesnæs, H. Wenzel, B.M. Petersen, Life cycle assessment of biogas from separated slurry, Environmental project 1329 (2010).

[30] Fichtner, The Viability of Advanced Thermal Treatment of MSW in the UK, Fichtner Consulting Engineers Ltd (2004).

[31] Danish Energy Agency (DEA), Technology data for energy plants, Copenhagen (Denmark): Energistyrelsen (Danish Energy agency) (2010).

[32] N. Jungbluth, M. Chudacoff, A. Dauriat, F. Dinkel, G. Doka, E.M. Faist, E. Gnansounou, N. Kljun, K. Schleiss, M. Spielmann, C. Stettler, J. Sutter, Life Cycle Inventories of Bioenergy, Swiss Centre for Life Cycle Inventories, ESU-services, Uster, CH Ecoinvent report No 17 (2007).

[33] DONG energy, Avedoerevaerket - Groent regnskab 2008, DONG energy; Hvidovre, Denmark ROS $432-0007$ (2009).

[34] M. Nielsen, O.-. Nielsen, M. Thomsen, Emissions from decentralised CHP plants 2007, Energinet. dk Environmental project no. 07/1882. Project report 5 - Emission factors and emission inventory for decentralised CHP production. National Environmental Research Institute, Aarhus University. 113 pp. - NERI Technical report No. 786. http://www.dmu.dk/Pub/FR786.pdf (2010).

[35] P. Kofman, R. Spinelli, Storage and handling of willow from SRC, ELSAMPROJEKT 87-986376-2-2 (1997).

[36] I.R. Emery, N.S. Mosier, The impact of dry matter loss during herbaceous biomass storage on net greenhouse gas emissions from biofuel production, Biomass \& bioenergy, available on-line (2012).

[37] IPCC, Chapter 11: N2O emissions from managed soils and CO2 emissions from lime and urea application, in: Anonymous 2006 IPCC Guidelines for National Greenhouse Gas Inventories, 2006.

[38] B. Amon, V. Kryvoruchko, T. Amon, S. Zechmeister-Boltenstern, Methane, nitrous oxide and ammonia emissions during storage and after application of dairy cattle slurry and influence of slurry treatment, Agriculture, ecosystems \& environment 112 (2006) 153-162.

[39] J. Clemens, M. Trimborn, P. Weiland, B. Amon, Mitigation of greenhouse gas emissions by anaerobic digestion of cattle slurry, Agriculture, ecosystems \& environment 112 (2006) 171-177.

[40] T. Matsunaka, T. Sawamoto, H. Ishimura, K. Takakura, A. Takekawa, Efficient use of digested cattle slurry from biogas plant with respect to nitrogen recycling in grassland, Int. Congr. Ser. 1293 (2006) 242-252.

[41] S. Bruun, T.L. Hansen, T.H. Christensen, J. Magid, L.S. Jensen, Application of processed organic municipal solid waste on agricultural land - A scenario analysis, Environ Model Assess 11 (2006) 251-265. 